\title{
A New Sustainability Controlling Approach for Urban Water Systems: Multidimensional Risk Identification and System Analysis
}

\author{
Michael Eller ${ }^{1}$, Jessica Beck ${ }^{1}$, Malte Hedrich ${ }^{2}$ and Wilhelm Urban ${ }^{1}$ \\ 1. Institute IWAR, Department of Water Supply and Groundwater Protection, Technical University of Darmstadt, Darmstadt 64287, \\ Germany \\ 2. Institute of Infrastructure and Resources Management, University Leipzig, Leipzig 04109, Germany
}

\begin{abstract}
There are many pressures on urban water systems in today's highly dynamic world. These include the diverse impacts that are summarized under the term "Global Change". At the same time, high demands on water utilities to act sustainably do exist. For this purpose, the collaborative project "Sustainability Controlling for Urban Water Systems" (NaCoSi) introduces an innovative approach with which sustainability risks can be identified and controlled. The sustainability controlling is based on common process-oriented management systems. The starting point is a system of sustainability objectives, which were developed together with practice partners from the German water sector. A method for multidimensional risk identification is introduced to identify sustainability risks. Complex networks of cause-effect relationships are disaggregated into unbranched linear causal chains, which are managed as records in a risk database. The subsequent analysis of the risk database allows the examination of cross-linked risks. Severe risk factors, vulnerable processes and sustainability objectives can thereby be identified and subsequently analyzed. The sustainability controlling was successfully tested and improved by an iterative process of case studies in cooperation with practice partners. The results of the case studies demonstrate the benefit of the project's interdisciplinary approach and the applicability of the sustainability controlling.
\end{abstract}

Key words: Sustainability controlling, sustainability risks, urban water management, risk identification, transdisciplinary.

\section{Introduction}

The inherited socio-technical urban water system, which has grown over many decades, is increasingly under pressure to change. Urban water management is facing major challenges due to increasing uncertainties and changing boundary conditions. In addition to the increasing demands for resource efficiency and sustainability, there are particular risks that arise, for instance, from demographic change, climate change or shifting regulatory circumstances [1-3]. Failure of climate change mitigation and water crises are ranked as most significant long-term risks [4]. The long useful life of the technical

Corresponding author: Michael Eller, Dipl.-Ing., research scientist, main research field: water and environment, environmental engineering. infrastructures of urban water systems affiliated with their high investment costs and long depreciation periods make clear-sighted planning essential. Strategic decisions pertaining to water infrastructures have direct and indirect environmental and societal impacts. Hence, poorly chosen decisions draw significant consequences for both the environment and the society [5]. As the outcome of today's action will become apparent after decades, the time to act is now. When planning measures, it is all the more important to pursue a comprehensive, holistic approach, in which the changing boundary conditions are taken into consideration [6]. Against this background, urban water service providers and decision-makers face a range of risks that affect the achievement of a sustainable urban water management. In order to meet the above-mentioned challenges, several management 
systems are currently used. They all cope with their specific field of application, but they do not fit the requirements for the holistic approach of sustainable urban water management. Traditionally, economic and engineering considerations have dominated decision making. Common methodologies mainly deal with analytical and objective parameters [7]. Currently, neither quality management nor environmental management nor benchmarking is capable of systematically identifying and assessing multidimensional sustainability risks [8].

This paper introduces a conceptual framework for risk-based sustainability controlling as a result of the collaborative project "Sustainability Controlling for Urban Water Systems” (NaCoSi) which has been funded by the German Federal Ministry of Research and Education. The sustainability controlling is meant to help urban water service providers to identify, analyze and evaluate risks in a comprehensive manner and to further develop measures for risk mitigation. Firstly, the applied methodology will be introduced with a focus on the multidimensional risk identification. Afterwards, case studies will be presented which supported the development of the approach in cooperation with 12 practice partners from the German water sector.

\section{A Conceptual Framework for Sustainability Controlling}

As Lundie and Ashbolt note, "sustainability is not a state to be arrived at but a broad evaluative framework for understanding and justifying social practice" [7]. Sustainable water management is therefore not about achieving an end point, but is rather the processes of influencing thinking and acting of decision-makers and stakeholders [9]. There are several approaches for sustainable urban water management, which intend to reach sustainable conditions by fulfilling sustainability criteria [10] or measuring achievements via indicators [11-13]. The NaCoSi sustainability controlling adopts a different approach: risks that endanger sustainability objectives-sustainability risks-should be managed and minimized in the process of risk management [14]. By constant control and regulation, a long-term transformation towards sustainable urban water management can be promoted. The NaCoSi sustainability controlling conceptual framework is based on standard risk management systems [15] and consists of different interacting steps which in turn include several methods (Fig. 1).

For a successful controlling, the first step should be to define a direction of where to steer the enterprise. Thus, the determination of sustainability objectives is essential for the sustainability controlling (see 2.1). The next step of risk assessment consists of four subsequent and repetitive processes. Firstly, sustainability risks are identified using a causal chain concept (see 2.2). Secondly, for the identified risks, the relevant information is gathered during the data collection via an online platform. The data are processed during the third step, risk analysis and evaluation. The risks for every objective category are plotted and compared by using risk matrices. To outline the overall risk situation of the company at a glance, the aggregated risk levels of all objective categories are plotted as radar charts. These risk profiles give an overview of vulnerable sustainability objectives and the risk distribution of the company.

As fourth step, for each risk, a performance indicator is used to monitor its effect on the respective

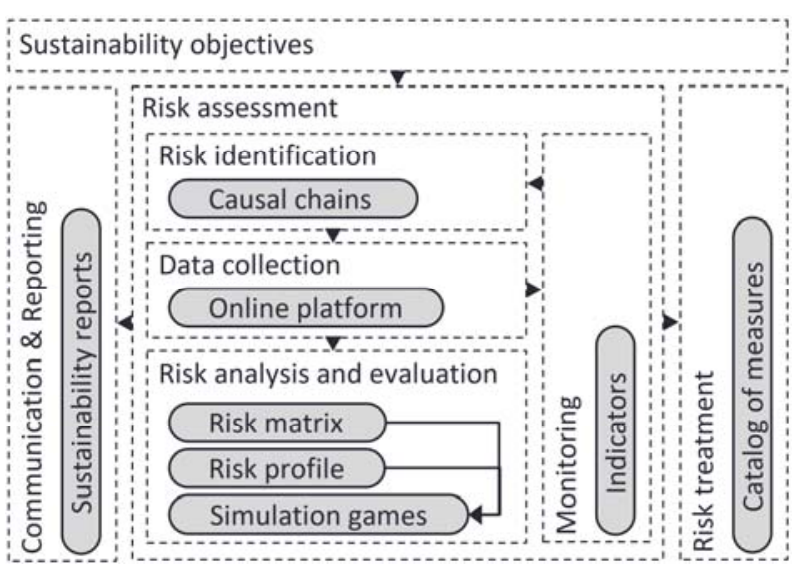

Fig. 1 Sustainability Controlling Conceptual Framework (author's own work). 

Identification and System Analysis

sustainability objective. Trend analysis can be conducted using indicator time series. With the help of indicator tendencies, sustainability risks can be validated or unconsidered risks can be revealed and included in the next phase of risk identification.

Based on the results of the risk analysis, scenario-based simulation games have been used to anticipate future worst-case scenarios and to derive possible strategies to face the situations involving risks.

The results of the risk assessment are condensed in sustainability reports that can be used for internal or external communication and provide valuable information for strategy development and risk treatment. A supplementary outcome of the $\mathrm{NaCoSi}$ project is a catalog of measures for common risk situations of urban water service providers.

The sustainability objectives and the risk identification by causal chains will be further described below.

\subsection{Sustainability Objectives for the Urban Water Sector}

The starting point is a system of sustainability objectives which serves for the operationalization of sustainability within urban water management. The multidisciplinary research team (consisting of technical, economic and socio-ecological research facilities) together with the practice partners elaborated a common and applicable sustainability concept for the urban water sector. The developed multidimensional sustainability objective system is divided into five objective categories: resource use, organization and technology, employees, corporate responsibility and viability. Each category consists of different sustainability objectives (Fig. 2). Thereby, the suggested objectives have no normative character. Before any implementation is performed, the objective system should be carefully checked and aligned with the specific prerequisites.

\subsection{Multidimensional Risk Identification by Causal Chains}

Risk assessment provides an improved understanding of risks that could affect the achievement of the suggested objectives. For the purpose of risk assessment, risks have to be initially identified in order to be subsequently analyzed and evaluated. As urban water systems may be considered as complex socio-technic and socio-economic systems, the risk environments of water systems are very diverse. Therefore, a method for risk identification has been developed which allows the diverse risk factors and risk pathways to be systematically captured, in order to make them accessible for a subsequent risk analysis. It allows to initially regard single, isolated risks and afterwards
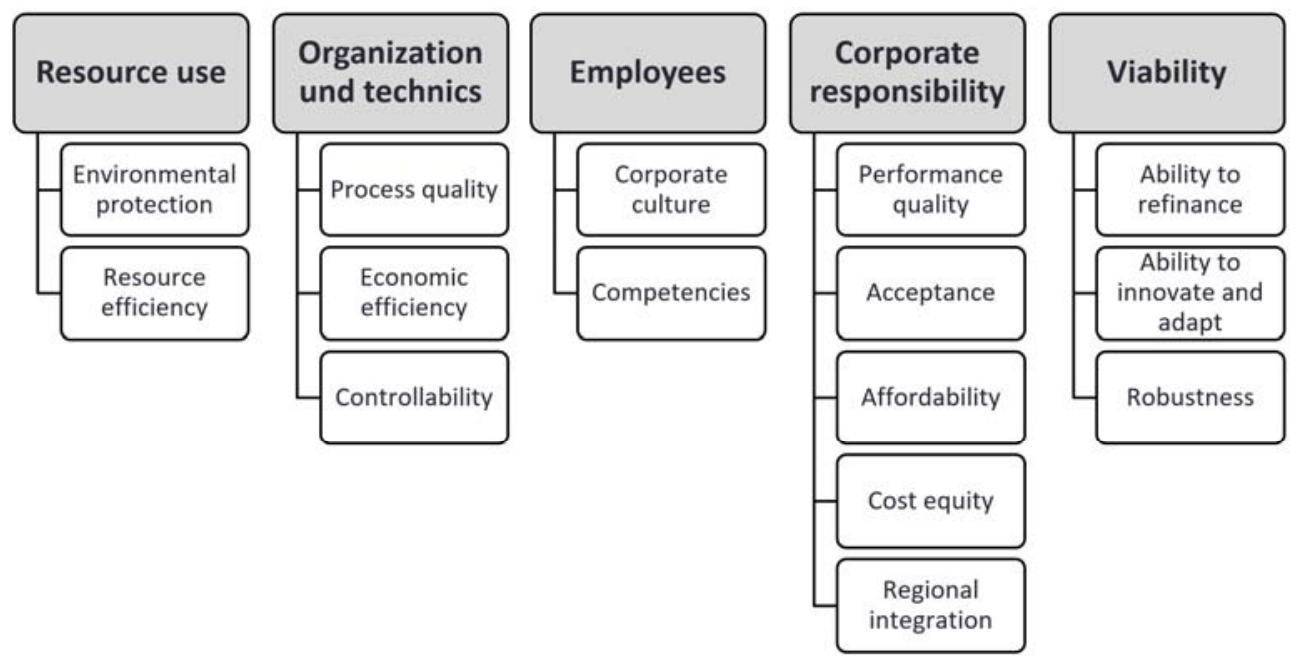

Fig. 2 Sustainability objectives for the urban water sector (adapted after [16]). 


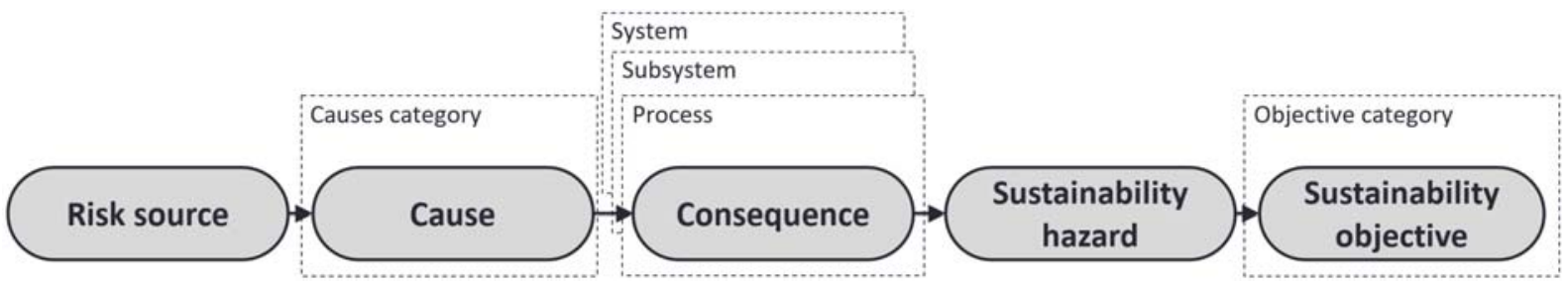

Fig. 3 Causal chain scheme for risk identification (author's own work).

to picture and analyze complex risk networks [17]. Instead of trying to capture complex networks on the whole, unbranched, linear causal chains are collected, which can be managed as records in a risk database. A straight-line modular system is applied to model relationships between risk causes and respective affected sustainability objectives. Thus, each causal chain describes one isolated sustainability risk and consists of determined consecutive elements (Fig. 3).

The elements of cause, consequence and sustainability objective constitute the core components of each causal chain whereas the other elements and categories provide supplemental information and allow to refine the subsequent risk analysis. In order to monitor deviations from the respective sustainability goals, an indicator is assigned to each causal chain. Thereby the subjective, foresighted risk analysis can be verified in a retrospective manner.

\subsection{Compiling Risk Networks}

As a result of the risk identification process via causal chains, an extensive risk database can be compiled which serves the subsequent in-depth risk analysis. Risk analysis is about developing a deeper understanding of the identified risks. By re-combining the straight-line causal chains, even complex cause-effect networks can now be delineated and will reveal the interconnections of sustainability risks (Fig. 4).

Applying network analysis methods or classification rules, it can be analyzed whether a certain cause affects several sustainability objectives or whether a sustainability objective is affected by various causes. Thereby, combined causes can strengthen or attenuate affected risks. Severe risk factors, vulnerable processes and sustainability goals can thus be identified. This information can be used for the following risk prevention and treatment. The identified risks are visually ranked by risk matrices, which are commonly used as a risk screening tool [18], and compiled for each sustainability goal or category. Risk profiles depict the risk situation at a glance as the risks are summarized for each sustainability goal or category and plotted as radar charts.

The analyzed risks are subsequently evaluated. For this purpose, scenario-based simulation games have been developed (an approach that will not be elaborated in this paper). As an outcome, a catalogue of measures can be derived. The results of the risk assessment are summarized in sustainability reports as successful risk assessment is dependent on effective communication and consultation with stakeholders.

\section{Case Studies}

Throughout the project duration, great importance was attached to cooperation between research and practice partners. Therefore, the sustainability controlling was developed and tested in case studies with 12 practice partners from the German water sector. The aim of the case studies was to improve the

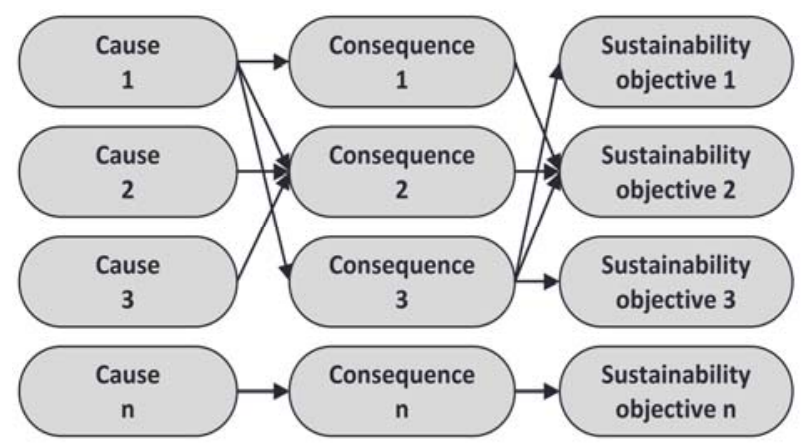

Fig. 4 Example causal network consisting of causal chains (author's own work). 


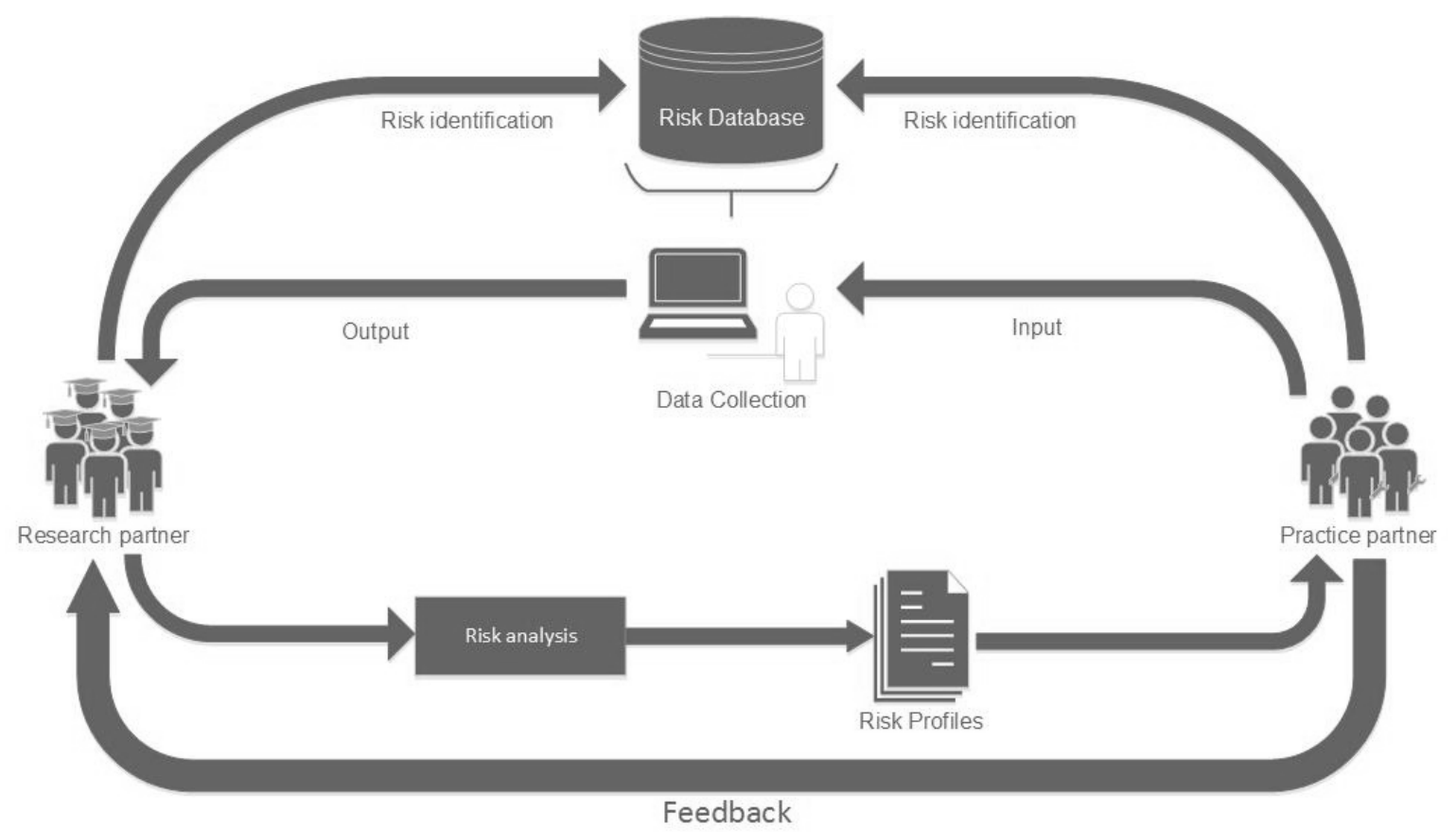

Fig. 5 Scheme of the case studies in NaCoSi (author's own work).

sustainability risk controlling tool by cross-fertilization between research and practice. They were designed as an iterative process of testing and reworking the tool. The joint development by both research and practice enables a streamlined future implementation and to bridge the gap between academia and practice. Fig. 5 describes the applied scheme of the case studies.

The first step regarding the case studies was the development of a risk database by means of risk identification utilizing the causal chain approach as described above in 2.2. It was conducted by the research partners by considering the key input of the practice partners. The joint risk identification ensured that relevant topics and risks of urban water services are considered in the risk database.

The main part of the case studies focuses on the application of the sustainability controlling tool, which was tested and reworked in an iterative two-step process. The sustainability controlling tool is based on the risk database. For the application of the tool, the risk information of the practice partners was collected. The data collection was conducted via an online platform and carried out by the practice partners. Afterwards, the data were evaluated and analyzed by the research partners in the process of risk analysis. The results of the data evaluation are company-specific risk profiles for each practice partner.

The practice partners were given the opportunity to express feedback, criticisms and wishes on the data collection, data evaluation and the risk profiles in workshops and simulation games after the first pilot application. Then, the feedback from the practice partners was implemented. The performed changes were tested in a second phase of data collection and evaluation.

Hence, as a result, the case studies with the appropriate feedback have great relevance for successful applicability and implementation of the sustainability controlling within the company's management process. The tool is improved by an iterative process and by cooperation with the practice partners. In consequence, the sustainability risk controlling is an instrument that is designed by and for urban water service providers, and which is compatible with their specific requirements. 


\section{Results and Discussion}

During the case studies, the interest and active contribution was great with respect to designing the sustainability controlling of the practice partners. The transdisciplinary approach - the early cooperation between research and practice-brought an important benefit for the project by cross-fertilization as well as the interdisciplinary activity of the research team. The practice partners made valuable contributions to the risk database and helped with constructive criticism to improve and to adapt the sustainability controlling tool to the individual requirements of urban water management.

At the end, the results of the case studies demonstrated that the sustainability controlling approach is applicable to urban water service providers. The risk database and the sustainability controlling tools allow the users a change of perspective on topics of sustainability. Furthermore, they give important impulses to discuss topics which go beyond economic and technical issues within the company as well as with other urban water service providers during the workshops. The exchange between different providers supports the definition of measures and the dealings with sustainability risks. The risk understanding of the users is broadened and positive incentives for changes within the company are created. The sustainability controlling approach may be implemented with the assistance of consultant or benchmarking companies or by the departments controlling utilities.

\section{Conclusion}

Standard risk management methods could be successfully enhanced to include a sustainability perspective. The users do not only deal with economic, technical and monetary business risks, but also with risks which concern social and ecological aspects. The discussion of these identified risks within the company creates an additional benefit because the company is able to deal with possible changes and their extensive effects in an early stage which avoids future costs. Thus, long-term developments can be taken into account for the strategic planning, which is particularly relevant for the costly technical infrastructures of urban water systems. Further, the developed sustainability controlling approach supports the transformation towards sustainable urban water management.

\section{Acknowledgements}

The research for this paper was carried out as part of the collaborative project "Sustainability Controlling for Urban Water Systems” (NaCoSi), which is a part of the research program "Smart and Multifunctional Infrastructural Systems for Sustainable Water Supply, Sanitation and Stormwater Management” (INIS), funded by the German Federal Ministry of Research and Education (BMBF). The authors would like to express their great appreciation to all research partners for their valuable contributions and in particular to the twelve water and sewerage service providers that were participating as practice partners.

\section{References}

[1] DWA. 2008. Demografischer Wandel: Herausforderungen und Chancen für die Deutsche Wasserwirtschaft. Hennef: DWA Deutsche Vereinigung für Wasserwirtschaft, Abwasser und Abfall e.V. (in German)

[2] Tränckner, J., Koegst, T., and Nowack, M. 2012. Auswirkungen des demografischen Wandels auf die Siedlungsentwässerung (DEMOWAS): Abschlussbericht. Dresden: Technische Universität Dresden. (in German)

[3] Hillenbrand, T., Niederste-Hollenberg, J., Menger-Krug, E., Klug, S., Holländer, R., Lautenschläger, S., et al. 2010. Demografischer Wandel als Herausforderung für die Sicherung und Entwicklung einer kosten- und ressourceneffizienten Abwasserinfrastruktur. Dessau-Roßlau: Umweltbundesamt. (in German)

[4] World Economic Forum. 2016. Global Risk report 2016. Geneva: World Economic Forum.

[5] Marlow, D. R., Beale, D. J., Cook, S., and Sharma, A. 2015. "Investing in the Water Infrastructure of Tomorrow. Understanding and Managing Urban Water in Transition.” Global Issues in Water Policy 15: 217-236.

[6] Londong, J., Hillenbrand, T., and Niederste-Hollenberg, J. 2011. "Demografischer Wandel: Anlass und Chance für 

Identification and System Analysis

Innovationen in der Wasserwirtschaft.“ KA Abwasser Abfall 58 (2): 152. (in German)

[7] Lundie, S., Ashbolt, N., Livingston, D., Lai, E., Kärrman, E., Blaikie, J., et al. 2008. Methodology for Evaluating the Overall Sustainability of Urban Water Systems: Sustainability Framework. Melbourne: Water Services Association of Australia.

[8] Beck, J., Eller, M., Geyler, S., Hedrich, M., Holländer, R., Jansky, N., et al. 2015. "Nachhaltigkeitscontrolling in der Siedlungswasserwirtschaft.” DVGW Energie Wasser Praxis 66 (4): 28-30. (in German)

[9] Pearson, L. J., Coggan, A., Proctor, W., and Smith, T. F. 2009. "A Sustainable Decision Support Framework for Urban Water Management.” Water Resources Management 24 (2): 363-376.

[10] Foxon, T. J., Mcilkenny, G., Gilmour, D., Oltean-Dumbrava, C., Souter, N., Ashley, R., et al. 2002. "Sustainability Criteria for Decision Support in the UK Water Industry.” Journal of Environmental Planning and Management 45 (2): 285-301.

[11] Bossel, H. 1999. Indicators for Sustainable Development: Theory, Method, Applications. Winnipeg: International Institute for Sustainable Development.
[12] Rahdari, A. H. and Anvary Rostamy, A. A. 2015. "Designing a General Set of Sustainability Indicators at the Corporate Level.” Journal of Cleaner Production 108 Part A: 757-771.

[13] Marques, R. C., da Cruz, N. F., and Pires, J. 2015. "Measuring the Sustainability of Urban Water Services." Environmental Science \& Policy 54: 142-151.

[14] Benz, P. 2014. "Konzept zum Nachhaltigkeitscontrolling in der Siedlungswasserwirtschaft.” Ph.D. thesis, Institute IWAR, Technische Universität Darmstadt. (in German)

[15] ISO 31000:2009. Risk management.

[16] Eller, M., Geyler, S., Jansky, N., Kerber, H., Lux, A., Möller, K., et al. 2014. "Nachhaltigkeitsziele und Risiken für siedlungswasserwirtschaftliche Unternehmen: erste Bausteine für ein Nachhaltigkeitscontrolling.” ISOE-Diskussionspapiere 37. (in German)

[17] Geyler, S., Lux, A., Möller, K., Tocha, C., Hedrich, M., Sonnenburg, A., et al. 2015. "Sustainability Controlling for Urban Water Systems." In Proc of the Cities of the Future Conference-Transitions to the Urban Water Services of Tomorrow (TRUST), 205-211.

[18] ISO 31010:2009. Risk Management-Risk Assessment Techniques. 